\title{
NCOA1 promotes angiogenesis in breast tumors by simultaneously enhancing both HIF1a- and AP-1-mediated VEGFa transcription
}

\author{
Li Qin ${ }^{1}$, Yan $X u^{2,3}$, Yixiang $X \mathbf{u}^{1,4}$, Gang Ma ${ }^{1}$, Lan Liao ${ }^{1}$, Yelin Wu ${ }^{1,5}, \mathbf{Y i ~ L i}^{6}$, Xian Wang ${ }^{6}$, \\ Xiaosong Wang ${ }^{6}$, Jun Jiang ${ }^{3}$, Jin Wang ${ }^{7}$, Jianming $\mathbf{X u}^{1,8}$ \\ ${ }^{1}$ Department of Molecular and Cellular Biology, Baylor College of Medicine, Houston, TX, USA \\ ${ }^{2}$ Department of Breast and Thyroid Surgery, Daping Hospital, Third Military Medical University, Chongqing, China \\ ${ }^{3}$ Breast Disease Center, Southwest Hospital, Third Military Medical University, Chongqing, China \\ ${ }^{4}$ Institute of Biosciences and Technology, Texas A\&M University Health Science Center, Houston, TX, USA \\ ${ }^{5}$ Shanghai Key Laboratory of Regulatory Biology, Institute of Biomedical Sciences, School of Life Sciences, East China Normal \\ University, Shanghai, China \\ ${ }^{6}$ Lester and Sue Smith Breast Center, Baylor College of Medicine, Houston, TX, USA \\ ${ }^{7}$ Department of Pharmacology, Baylor College of Medicine, Houston, TX, USA \\ ${ }^{8}$ Institute for Cancer Medicine and College of Basic Medical Sciences, Sichuan Medical University, Luzhou, Sichuan, China \\ Correspondence to: \\ Jianming Xu, e-mail: jxu@bcm.edu \\ Li Qin, e-mail: lqin1@bcm.edu \\ Keywords: NCOA1, VEGFa, transcriptional regulation, breast cancer \\ Received: March 04, $2015 \quad$ Accepted: June 09, $2015 \quad$ Published: June 20, 2015
}

\section{ABSTRACT}

Nuclear receptor coactivator 1 (NCOA1) is overexpressed in a subset of breast cancer and its increased expression positively correlates with disease recurrence and metastasis. Although NCOA1 is known to promote breast cancer metastasis through working with multiple transcription factors to upregulate the expression of Twist1, ITGA5, CSF-1, SDF1 and CXCR4, the role of NCOA1 in breast tumor angiogenesis has not been investigated. In this study, we found that the microvascular density (MVD) was significantly decreased and increased in Ncoa1-knockout and NCOA1-overexpressing mammary tumors, respectively, in several breast cancer mouse models. Knockout or knockdown of NCOA1 in breast cancer cell lines also markedly compromised their capability to induce angiogenesis in Matrigel plugs embedded subcutaneously in mice, while this compromised capability could be rescued by VEGFa treatment. At the molecular level, NCOA1 upregulates VEGFa expression in both mouse mammary tumors and cultured breast cancer cells, and it does so by associating with both c-Fos, which is recruited to the AP-1 site at bp -938 of the VEGFa promoter, and HIF1a, which is recruited to the HIF1a-binding element at bp -979 of the VEGFa promoter, to enhance VEGFa transcription. In 140 human breast tumors, high NCOA1 protein correlates with high MVD and patients with both high NCOA1 and high MVD showed significantly shorter survival time. In summary, this study revealed a novel mechanism that NCOA1 potentiates breast cancer angiogenesis through upregulating HIF1a and AP-1-mediated VEGFa expression, which reinforces the rational of targeting NCOA1 in controlling breast cancer progression and metastasis.

\section{INTRODUCTION}

The nuclear receptor coactivator 1 (NCOA1 or SRC-1) belongs to the p160 SRC family that also includes NCOA2 (TIF2, GRIP1, SRC-2) and NCOA3 (SRC-3,
AIB1, RAC3, ACTR) [1, 2]. These coactivators interact with nuclear receptors and certain other transcription factors (TFs) to recruit acetyltransferases such as CBP and p300 and methyltransferases such as CARM1 and PRMT1 to the enhancer for programing histone codes associated with 
active transcription [3-5]. These SRC coactivators not only play pivotal roles in development, growth, reproduction and metabolism, but also play crucial roles in cancer [2]. The oncogenic role of NCOA3 has been well established in various animal models and human cancers such as breast, prostate, colorectal and endometrial cancers $[2$, $6-8]$. In breast cancer, NCOA3 is overexpressed and its overexpression is associated with HER2 activation, endocrine therapy resistance and poor disease-free survival (DFS) $[2,6,9]$. Knockout of Ncoa3 in mice significantly inhibits H-ras-, HER2- and chemical carcinogen-induced mammary tumorigenesis $[10,11]$. Accordingly, overexpression of NCOA3 causes spontaneous development of mammary tumors [12]. At the molecular level, NCOA3 up-regulates the expression of multiple genes including cyclin D1, MMP-2, MMP-9 and macrophage migration inhibitory factor (MIF) $[2,13,14]$. Furthermore, SRC-3delta4, a splicing variant of NCOA3, can bridge EGFR to phosphorylate and activate FAK, which potentiates cancer cell survival, proliferation, migration and invasion [15]. NCOA1 is also overexpressed in $19-29 \%$ of human breast tumors and its overexpression positively correlates with HER2 expression, lymph node metastasis, disease recurrence and poor survival [16-18]. Although overexpression of NCOA1 in the mouse mammary gland is not oncogenic by itself and is also incapable of promoting oncogene-induced tumor growth, it significantly increased lung metastasis in Tg(MMTVPyMT) (transgenic mouse mammary tumor virus-polyoma middle $\mathrm{T}$ ) and $\mathrm{Tg}(\mathrm{MMTV}-\mathrm{Neu})$ breast cancer mouse models [19]. Inversely, knockout of Ncoal remarkably inhibits lung metastasis without affecting primary mammary tumor growth in $\operatorname{Tg}($ MMTV-PyMT) mice [20]. Mechanistically, NCOA1 has been shown to up-regulate Twist1, ITGA5, CSF-1, SDF1 and CXCR4 expression, which are partially responsible for promoting metastasis through potentiating breast tumor cell epithelial-mesenchymal transition (EMT), migration, invasion and macrophage recruitment $[19,21-$ 23]. However, the specific role of NCOA1 in breast tumor angiogenesis, the hallmark of breast cancer progression to metastasis, remains to be defined.

Angiogenesis happens under both physiological conditions and pathological conditions [24]. Since tumor angiogenesis is required not only for providing oxygen and nutrients to support tumor growth but also for mediating tumor cell dissemination and metastasis to distant organs, it has been regarded as a fundamental step for a benign solid tumor to become a more malignant tumor [25]. Many angiogenic factors including PDGF, FGF, VEGF, TGF $\beta$, Ang1, Ang2, VE-cadherin, CD31 and plasminogen activators have been demonstrated to promote endothelial proliferation and differentiation, recruit vascular smooth muscle cells, remodel extracellular matrix and stabilize vascular structures [26]. The VEGF family with five members including VEGFa, VEGFb, VEGFc, VEGFd and PGF are crucial angiogenic factors [27]. VEGFa is frequently overexpressed in various human solid tumors
[28], which binds and activates its transmembrane tyrosine kinase receptors to promote endothelial proliferation, migration and invasion as well as vascular permeability [29, 30]. In addition, tumor cell-produced VEGFs can accelerate tumor cell progression and metastasis through stimulating tumor cell survival, migration and invasion, suppressing immune response and facilitating tumor cells homing to the bone marrow progenitors [31]. Several VEGF-targeted agents such as Bevacizumab have been applied to cancer therapy with clinical benefits when used alone or in combination with chemotherapy [28]. However, acquired resistance and induction of tumor invasiveness upon these treatments have emerged as major drawbacks of these applications [32]. Clearly, deep insights into understanding the mechanisms responsible for the transcriptional regulation of major angiogenic factors will help to yield more effective reagents for inhibiting angiogenesis.

Hypoxia in growing tumors stabilizes HIF $1 \alpha$ to up-regulate VEGF expression, which in turn stimulates tumor angiogenesis [33]. However, the coactivators that mediate HIF $1 \alpha$ transcriptional activity have not been fully characterized. In this study, we report that NCOA1 works with transcription factors HIF $1 \alpha$ and AP-1 (c-Jun/c-Fos) to promote VEGF $\alpha$ expression in breast cancer cells and drive breast tumor angiogenesis in both mouse and human breast tumors. Our findings suggest that NCOA1-promoted breast cancer metastasis may be related to its role in angiogenesis and thus NCOA1 may serve as a new molecular target for inhibiting breast tumor angiogenesis and metastasis.

\section{RESULTS}

\section{Ncoa1 expression positively correlates with microvascular density (MVD) in mouse mammary tumors}

To explore the relationship between Ncoa1 expression and mammary tumor angiogenesis, we examined MVD in mammary tumors developed in three previously established mouse models with normal Ncoal, Ncoal knockout or NCOA1 overexpression [19, 34-37] by immunostaining CD31, a molecular marker of endothelial cells. Semiquantitative analysis revealed that MVD is reduced $70 \%$ and $60 \%$ in Ncoal knockout $\left(\mathrm{Ncoa1}^{--}\right)$) mammary tumors versus Ncoal wild type $\left(\mathrm{Ncoal}^{+++}\right)$mammary tumors at week 8 and week 13 after the detection of palpable tumors in Tg(MMTV-PyMT) mice (Figure 1a and 1b). Consistently, MVD is remarkably increased in the mammary tumors with transgenic NCOA1 overexpression in $\mathrm{Tg}(\mathrm{MMTV}-\mathrm{NCOA} 1)$ $\times \operatorname{Tg}($ MMTV-TVA/RCAS-PyMT) mice versus mammary tumors with normal Ncoal expression in Tg(MMTV-TVA/ RCAS-PyMT) mice. In these mice, a subpopulation of the mammary epithelial cells with transgenic expression of TVA, a receptor for the RCAS avian virus, were specifically infected by the injected RCAS-PyMT avian virus and the 


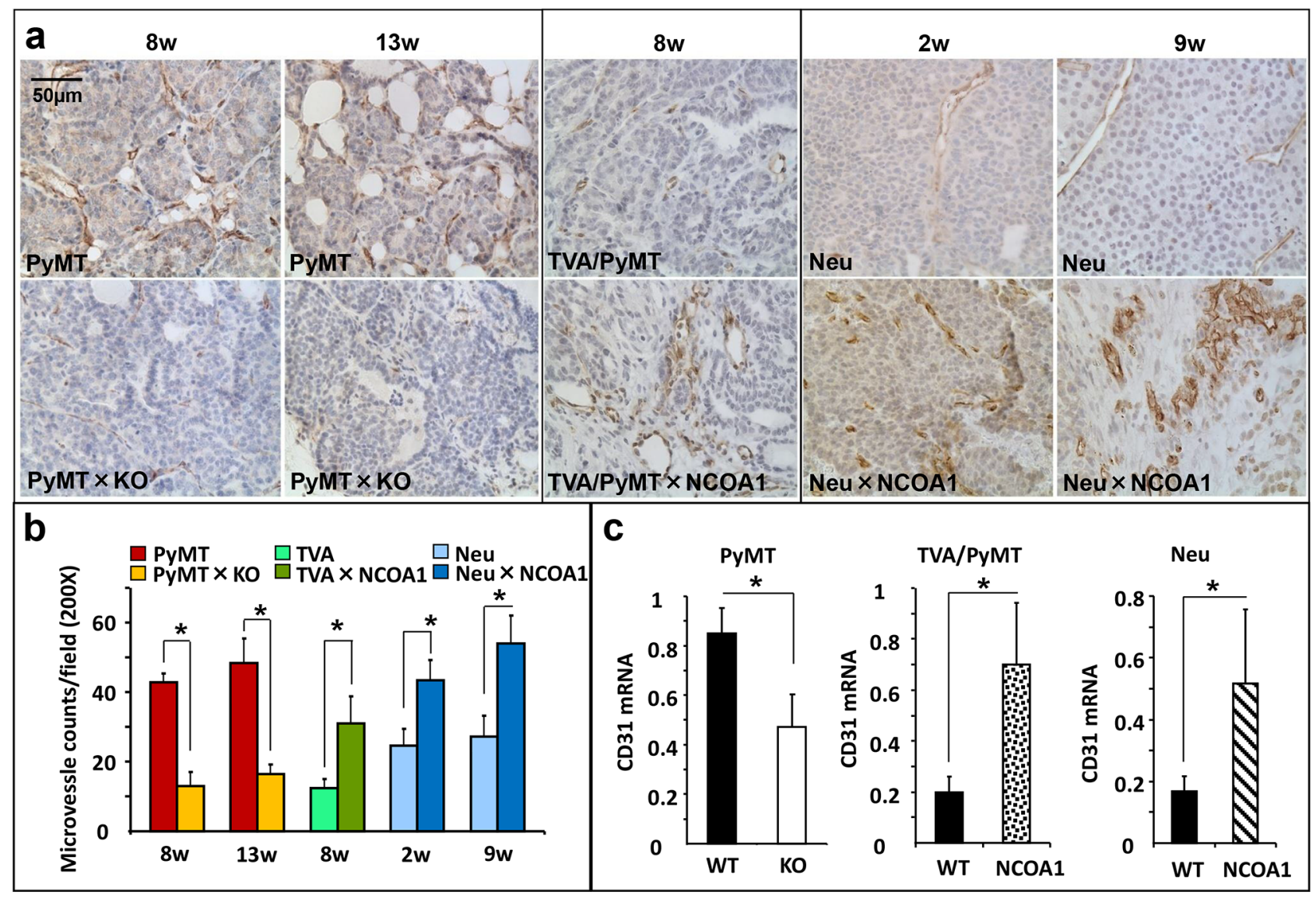

Figure 1: Microvascular density (MVD) in mouse mammary tumors with Ncoa1 knockout or overexpression. a. Detection of CD31-positive endothelial cells by immunohistochemistry in mouse mammary tumor tissue sections prepared from Tg(MMTV-PyMT), Tg(MMTV-PyMT) $\times$ Ncoa1 $^{-/}$, Tg(MMTV-TVA/RCAS-PyMT $)$, Tg(MMTV-TVA/RCAS-PyMT) $\times$Tg(MMTV-NCOA1), Tg(MMTV$\mathrm{Neu})$ and $\mathrm{Tg}(\mathrm{MMTV}-\mathrm{Neu}) \times \mathrm{Tg}(\mathrm{MMTV}-\mathrm{NCOA} 1)$ mice as indicated. Tumors were isolated from mice after palpable tumors were detected for the time in weeks indicated. Scale bar: $50 \mu \mathrm{m}$. b. Semi-quantitative analysis of MVD. The total number of microvessels in 5 different viewing fields of $200 \times$ magnification under a microscope was counted for each tumor section. Sections from at least 10 tumors in each group were examined. Data are presented as Mean $\pm \mathrm{SD}$. ${ }^{*} p<0.05$ by Student's $t$ test. c. QPCR analysis of $C D 31$ mRNA in the mouse mammary tumors $(n=5)$ isolated from mice with the indicated genotypes. PyMT, Tg(MMTV-PyMT); TVA/PyMT, Tg(MMTV-TVA/ RCAS-PyMT); Neu, Tg(MMTV-Neu); WT, wild type; NCOA1, Tg(MMTV-NCOA1).

infected cells were transformed into tumor cells by PyMT expression [19, 34]. Furthermore, MVD is also significantly increased in NCOA1-overexpressing mammary tumors in $\operatorname{Tg}($ MMTV-NCOA1 $) \times \operatorname{Tg}($ MMTV-Neu $)$ mice versus mammary tumors with normal Ncoal expression in $\operatorname{Tg}($ MMTV-neu) mice at both week 2 and week 9 after the detection of palpable tumors (Figure 1a and 1b). Moreover, quantitative RT-PCR (QPCR) analysis revealed that the relative expression levels of CD31 mRNA is significantly reduced in $\mathrm{Ncoal}^{-/-} \times \mathrm{Tg}(\mathrm{MMTV}-\mathrm{PyMT})$ mouse mammary tumors with Ncoal knockout, but significantly increased in $\operatorname{Tg}($ MMTV-NCOA1 $) \times \operatorname{Tg}($ MMTV-TVA/RCAS-PyMT $)$ and $\operatorname{Tg}($ MMTV-NCOA1 $) \times \operatorname{Tg}($ MMTV-Neu $)$ mouse mammary tumors with NCOA1 overexpression when compared with their respective control tumors described above (Figure 1c). On the other hand, CD31 expression showed no significant changes in the mammary tumors $(n=5)$ of $\mathrm{Ncoa}^{-/-} \times$ $\operatorname{Tg}$ (MMTV-PyMT) mice when compared with the mammary tumors $(n=5)$ of $\operatorname{Tg}($ MMTV-PyMT) mice (data not shown).
These observations suggest that the density of endothelial cells with CD31 expression positively correlates with the levels of Ncoal expression, but not Ncoa3 expression in the mouse mammary tumors. Together, these results demonstrate that the level of Ncoal expression positively correlates with MVD in all three different mouse breast cancer models.

\section{NCOA1 is required for breast cancer cell-stimulated angiogenesis in vivo}

To determine whether Ncoal expressed in the mammary tumor cells supports angiogenesis, we performed in-gel-angiogenesis assay in mice to assess the angiogenesis-inducing capabilities of two Ncoal WT (W1 and W2) and two Ncoa1 knockout (K1 and K2) tumor cell lines, which were previously established from $\mathrm{Tg}\left(\right.$ MMTV-PyMT) and Ncoa1 ${ }^{-/} \times \mathrm{Tg}($ MMTVPyMT) mouse mammary tumors $[13,21]$. Subcutaneous injection of W1 or W2 cells into the clotted Matrigel plugs 
induced robust angiogenesis in the gel, while injection of same numbers of K1 or K2 cells induced very little angiogenesis under same conditions. In agreement with these observations, immunofluorescent staining for CD31 and Flk1, the two endothelial markers, identified many small blood vessels in the sections of Matrigel plugs injected with $\mathrm{W} 1$ or W2 cells, while the same staining only detected a few small blood vessels in the sections of Matrigel plugs injected with K1 or K2 cells (Figure 2a). The impaired angiogenesis in the gel plugs injected with $\mathrm{K} 1$ or K2 cells could be largely rescued by adding VEGFa into the Matrigel plugs, suggesting K1 and K2 cells do not produce enough VEGF for inducing angiogenesis (Figure 2b). Statistical analysis revealed significant decreases in MVDs induced by $\mathrm{K} 1$ or $\mathrm{K} 2$ cells versus that induced by $\mathrm{W} 1$ or W2 cells or by K1 or K2 cells supplemented with VEGFa (Figure 2c). Similarly, MDA-MB-231 human breast cancer cells expressing a non-targeting shRNA in the Matrigel plugs induced very active angiogenesis as indicated by the abundant red-colored blood vessels and CD31/Flk1-positive endothelial cells. However, MDA-MB-231 cells with stable knockdown of NCOA1 mRNA by expressing either of the two different shRNAs showed a very low capability to induce angiogenesis in the same Matrigel plugs (Figure 2d and 2e). These results demonstrate that NCOA1 expressed in both mouse and human breast cancer cells strongly promotes these cancer cell-induced angiogenesis in vivo.

\section{NCOA1 regulates VEGFa expression in breast cancer cells}

To identify potential angiogenic factors regulated by Ncoa1, we measured the expression levels of many angiogenic factors in mouse mammary tumor cells that either have no functional Ncoal or have different levels of Ncoa1. We found that VEGFa mRNA expression is 5 and 3 fold lower in K1 and K2 Ncoa1 knockout mouse mammary tumor cells than that in W1 and W2 Ncoa1 WT mouse mammary tumor cells, respectively. VEGFc mRNA is also reduced $60 \%$ and $25 \%$ in $\mathrm{K} 1$ and $\mathrm{K} 2$ cells versus $\mathrm{W} 1$ and $\mathrm{W} 2$ cells, respectively. In contrast, $\mathrm{VEGFb}$ mRNA levels in $\mathrm{K} 1$ and $\mathrm{K} 2$ cells are comparable to that in W1 and W2 cells (Figure 3a). In addition, the expression levels of VEGFR1, VEGFR2, PDGFa, PDGFb, integrin $\alpha_{\mathrm{y}} \beta_{3}$, FGFR1 and FGFR2 in K1 and $\mathrm{K} 2$ cells are also similar to that in $\mathrm{W} 1$ and $\mathrm{W} 2$ cells (data not shown). In agreement with these results obtained from $\mathrm{K} 1, \mathrm{~K} 2, \mathrm{~W} 1$ and $\mathrm{W} 2$ cells in culture, VEGFa expression is also reduced more than $60 \%$ in Ncoa1 knockout mammary tumors in $\mathrm{Ncoa1}^{-/} \times \mathrm{Tg}(\mathrm{MMTV}$-PyMT) mice versus Ncoa1 WT mammary tumors in Tg(MMTV-PyMT) mice. However, VEGFc expression levels showed no significant difference between these two types of mammary tumors (Figure 3b). Furthermore, the expression level of VEGFa mRNA, but not VEGFc mRNA, is increased more than 3 folds in NCOA1overexpressing mammary tumors in $\operatorname{Tg}(\mathrm{MMTV}-\mathrm{NCOA} 1) \times$
Tg(MMTV-TVA/RCAS-PyMT) mice when compared with that in Ncoal WT mammary tumors in Tg(MMTV-TVA/ RCAS-PyMT) mice (Figure 3c). Finally, we also measured VEGFa mRNA expressed in the mammary tumors with knockout of Ncoa3, another member of the SRC family. We found no significant difference in VEGFa mRNA expression levels between mammary tumors $(n=5)$ in Tg(MMTVPyMT $) \times \mathrm{Ncoa3}^{-/-}$mice and mammary tumors $(n=5)$ in Tg(MMTV-PyMT) mice (data not shown). Together, the consensus of these results indicates that VEGFa expression levels positively correlate with Ncoal expression levels in multiple breast cancer mouse models.

To validate the regulatory relationship between NCOA1 and VEGFa in breast cancer cells, we further tested whether expression of NCOA1 in K1 and K2 Ncoal knockout cells could restore VEGFa expression and whether silencing NCOA1 expression in mouse and human breast cancer cells could down-regulate VEGFa expression. Indeed, adenovirus-mediated NCOA1 expression robustly increased VEGFa expression in both $\mathrm{K} 1$ and K2 cells (Figure 3d), while knockdown of Ncoa1 in W1 and W2 cells using a commercially available siRNA Smart Pool kit markedly reduced VEGFa expression (Figure 3e). Knockdown of NCOA1 using two different shRNAs in MDA-MB-231 human breast cancer cells also drastically reduced both VEGFa mRNA expression and VEGFa protein secreted into the culture medium (Supplementary Figure S1 and Figure 3f). These results indicate that NCOA1 either directly or indirectly regulates VEGFa expression in multiple types of breast cancer cells.

\section{NCOA1 is recruited to the proximal regions of the $V E G F a$ promoter containing HIF1 $\alpha$ and AP-1 binding elements}

It is known that several transcription factors including HIF $1 \alpha$, c-Fos and NF- $\mathrm{\kappa B}$ are recruited to the proximal regions of the $V E G F a$ gene promoter to activate $V E G F a$ transcription (Figure 4a) [38-40]. Our chromatin immunoprecipitation (ChIP) assays confirmed that HIF $1 \alpha$, $\mathrm{c}-\mathrm{Fos}$ and NF- $\mathrm{kB}$ are associated with a chromatin region (Region B in Figure 4a) that is downstream of the TATA box of the VEGFa promoter in MDA-MB-231 cells and this region contains one HIF $1 \alpha$ binding element, two AP-1 elements and one NF- $\mathrm{KB}$ binding element. Furthermore, knockdown of HIF $1 \alpha$, c-Fos or NF-kB significantly reduced their recruitments to this chromatin region (Figure 4b), supporting the specific recruitments of these transcription factors to this chromatin region. In contrast, HIF $1 \alpha$, c-Fos and NF- $\kappa B$ are not associated with Region A with an AP-1 element and Regions $\mathrm{C}$ and D without any binding elements for these three transcription factors in the proximal regions of the $V E G F a$ promoter (Figure $4 \mathrm{a}$ and $4 \mathrm{~b}$ ). Importantly, ChIP assays also revealed an efficient recruitment of NCOA1 to Region B of the $V E G F a$ promoter in MDA-MB-231 cells, and this specific 


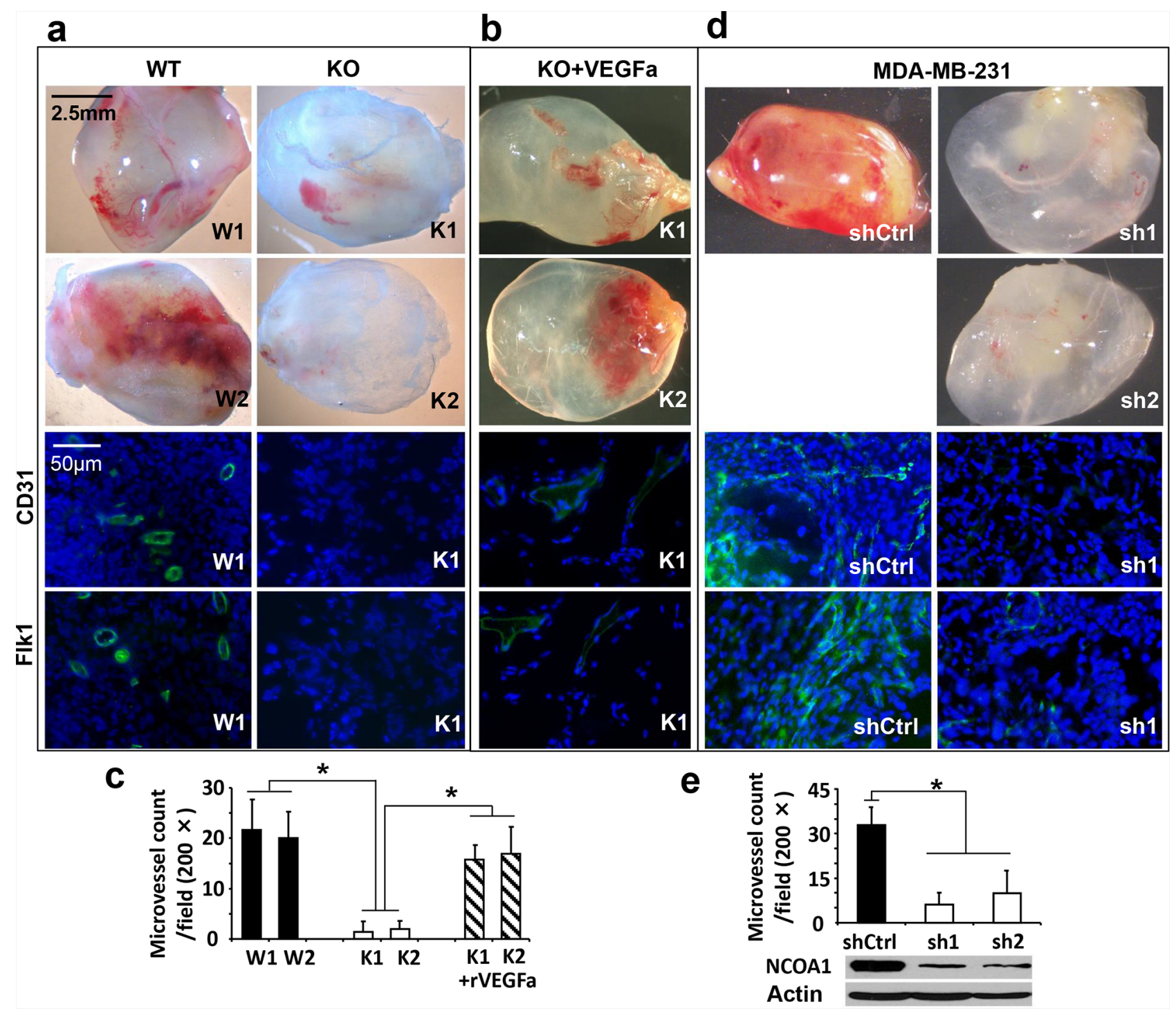

Figure 2: In vivo Matrigel angiogenesis induced by mouse and human breast tumor cells with Ncoa1 knockout and NCOA1 knockdown, respectively. a. Representative images of Matrigel plugs with angiogenesis induced by W1, W2, K1 and K2 cells in SCID/beige mice (upper four panels) and representative images of CD31 and Flk1 immunofluorescent staining (green color) and DAPI staining (blue color) of Matrigel plug sections with angiogenesis induced by W1 and K1 cells (lower four panels). b. Representative images of Matrigel plugs with angiogenesis induced by $\mathrm{K} 1$ and $\mathrm{K} 2$ cells as well as $10 \mathrm{nM}$ of recombinant VEGFa (rVEGFa) protein in Matrigel (upper two panels) and representative images of CD31 and Flk1 immunofluorescent staining and DAPI staining of Matrigel plug sections with angiogenesis induced by K1 cells plus rVEGFa (lower two panels). c. Semi-quantitative analysis of angiogenesis induced by W1, W2, K1 and K2 cells as well as K1 and K2 cells plus rVEGFa in Matrigel plugs in mice. A total of 12 Matrigel plugs with angiogenesis induced by the indicated cells with or without rVEGFa were analyzed. The number of microvessels per $200 \times$ viewing field was counted and 5 viewing fields were examined for each Matrigel plug. The data are presented as Mean \pm SD. ${ }^{*} p<0.05$ by Student's $t$ test. d. Representative images of Matrigel plugs with angiogenesis induced by MDA-MB-231 cells expressing non-targeting shRNA (shCtrl) or NCOA1 mRNA-targeting shRNAs (sh1 and sh2) and representative images of CD31 and Flk1 immunofluorescent staining and DAPI staining of Matrigel plug sections with angiogenesis induced by MDA-MB-231 cells expressing shCtrl or sh1. e. Semi-quantitative analysis of angiogenesis induced by MDA-MB-231 cells expressing shCtrl, sh1 or sh2 in Matrigel plugs. Microvessels in 6 Matrigel plugs for each group were examined and counted as described above. Data are presented as Mean $\pm \mathrm{SD}$. ${ }^{*} p<0.05$ by Student's $t$ test. The knockdown efficiency of NCOA1 was analyzed by Western blot.

association was confirmed by its decreased recruitment to this region in MDA-MB-231 cells with NCOA1 knockdown (Figure $4 \mathrm{~b}$ and $4 \mathrm{c}$ ). No NCOA1 was found to be associated with the proximal Regions A, C and D of the
$V E G F a$ promoter (Figure 4b). These results demonstrate that NCOA1 is associated with the same chromatin region that also associated with transcription factors activating $V E G F a$ expression. 

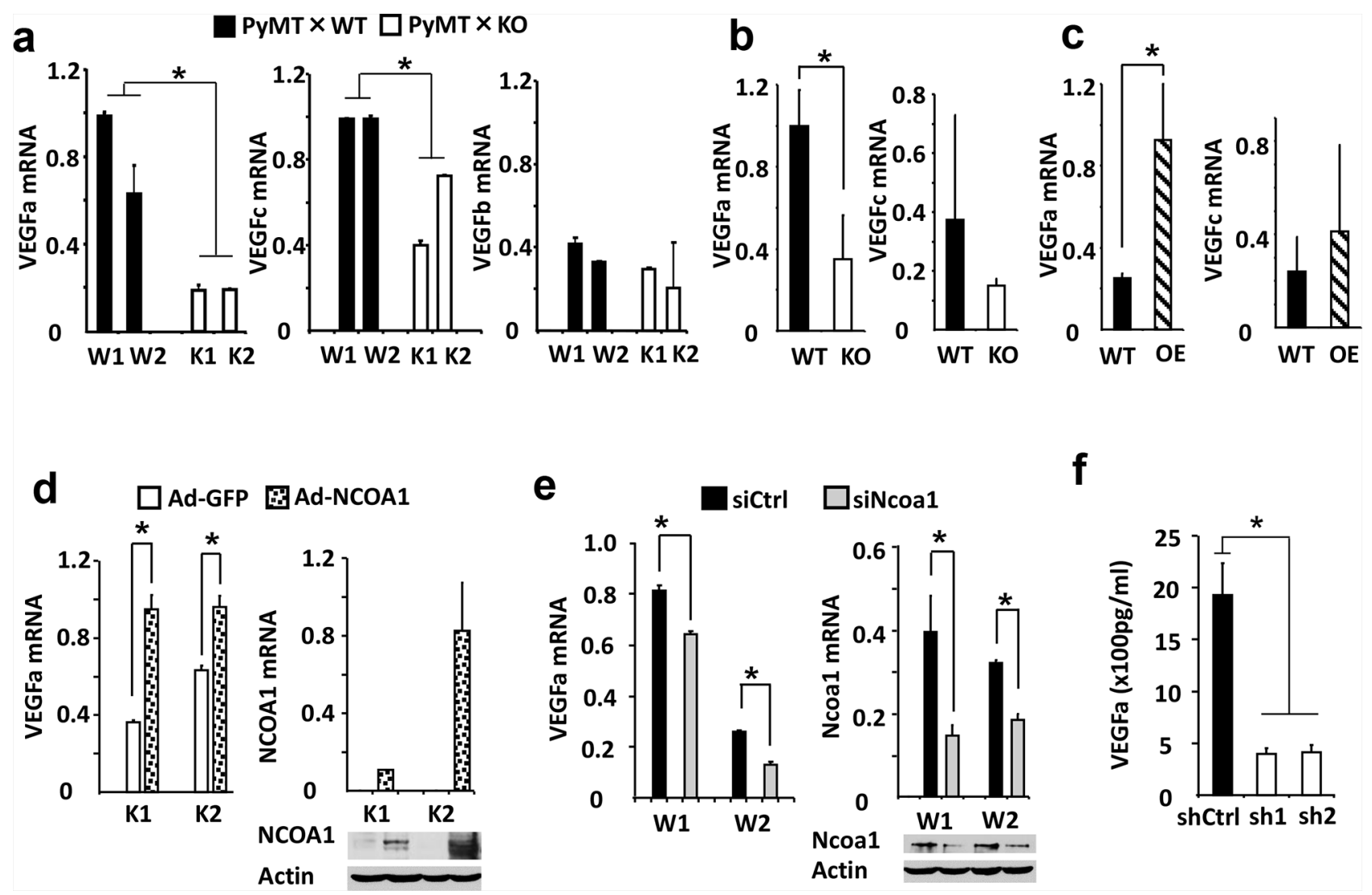

Figure 3: NCOA1 regulates VEGFa expression in breast tumor cells. a. Relative expression levels of $V E G F a, V E G F C$ and $V E G F b$ mRNAs in $\mathrm{W} 1, \mathrm{~W} 2, \mathrm{~K} 1$ and $\mathrm{K} 2$ cells measured by QPCR. b. Relative expression levels of $V E G F a$ and $V E G F c$ mRNAs in $\mathrm{Tg}(\mathrm{MMTV}-\mathrm{PyMT})(\mathrm{WT})$ and $\mathrm{Tg}(\mathrm{MMTV}-\mathrm{PyMT}) \times$ Ncoal $^{-/}(\mathrm{KO})$ mouse mammary tumors $(n=5)$ measured by QPCR. c. Relative expression levels of $V E G F a$ and $V E G F c$ mRNA levels in Tg(MMTV-TVA/RCAS-PyMT) (WT) and Tg(MMTV-TVA/RCAS-PyMT) $\times$ $\mathrm{Tg}$ (MMTV-NCOA1) (OE) mouse mammary tumors $(n=10)$ measured by QPCR. d. Relative expression levels of VEGFa mRNA in K1 and K2 cells with adenovirus-mediated GFP or NCOA1 expression (left panel). The expression levels of NCOA1 were analyzed by both QPCR and Western blotting (right panel). As expected, human NCOA1 mRNA was not expressed in the mouse K1 and K2 cells. e. Relative expression levels of VEGFa and Ncoal mRNAs in W1 and W2 cells transfected with siCtrl or Ncoa1 siRNAs as indicated. The measurement was carried out by QPCR. Ncoal knockdown efficiency was also analyzed by Western blotting. f. Secreted VEGFa concentrations in the conditioned media of MDA-MB-231 cells expressing non-targeting control shRNA (shCtrl) or NCOA1 mRNA-targeting shRNAs (sh1 and sh2). NCOA1 knockdown efficiency in these cells was shown in Figure 2e. The * in all panels indicates $p<0.05$ by Student's $t$ test.

To examine whether NCOA1 is recruited to chromatin Region B next to the VEGFa promoter by HIF1 $\alpha$, c-Fos and/ or NF- $\mathrm{BB}$, we performed ChIP assays using NCOA1 antibody in MDA-MB-231 cells with normal or silenced expression of HIF $1 \alpha$, c-Fos or NF- $\kappa$ B. Again, in MDA-MB-231 control cells transfected with a pool of non-targeting siRNAs, NCOA1 is efficiently recruited to the chromatin Region B (Figure $4 \mathrm{c}$ and $4 \mathrm{~d}$ ). When HIF1 $\alpha$ or c-Fos expression is silenced by siRNA transfection, the recruitment of NCOA1 to Region B is markedly reduced. In contrast, knockdown of NF- $\mathrm{kB}$ expression does not affect NCOA1 recruitment to the chromatin Region B proximal to the $V E G F a$ promoter (Figure $4 \mathrm{c}$ and $4 \mathrm{~d}$ ). It has been reported that SRC-1 (NCOA1) physically interacts with c-Jun and c-Fos to activate gene transcription [41]. Our co-immunoprecipitation assay also demonstrated that NCOA1 forms a protein complex with HIF1 $\alpha$ in MDA-MB-231 breast cancer cells (Figure 4e). Together, these results demonstrate that NCOA1 is mainly recruited to a proximal region of the $V E G F a$ promoter by associating with c-Jun, c-Fos and HIF $1 \alpha$.

\section{NCOA1 enhances HIF1 $\alpha$ and AP-1 mediated activation of the VEGFa promoter}

To determine whether NCOA1 could enhance the activity of the $V E G F a$ promoter, we constructed a $V E G F a$ promoter-luciferase (VP-Luc) reporter by using a $2 \mathrm{~kb}$ DNA fragment (bp -1986 to 96) known to contain sufficient $V E G F a$ promoter activity [42] and DNA elements associated with HIF1 $\alpha$, c-Fos and NCOA1 (Figure 4, and Figure 5a). Expression of NCOA1 in HeLa cells increased the activity of VP-Luc reporter in a dose-dependent manner. Expression of either HIF $1 \alpha$ or c-Fos with c-Jun in HeLa cells also slightly increased the activity of VP-Luc reporter. Importantly, co-expression of NCOA1 and HIF1 $\alpha$ or NCOA1, c-Fos and c-Jun synergistically increased the activity of VP-Luc 

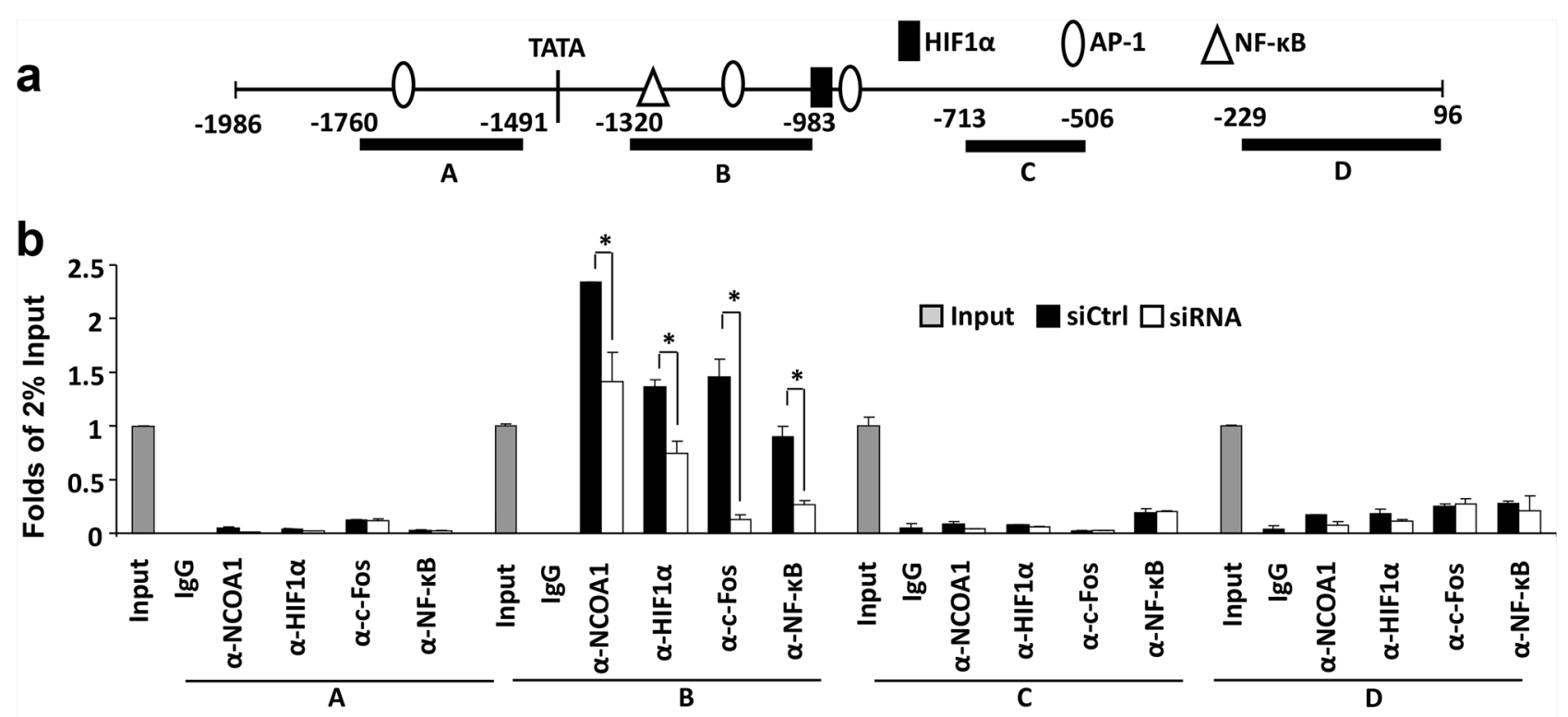

C

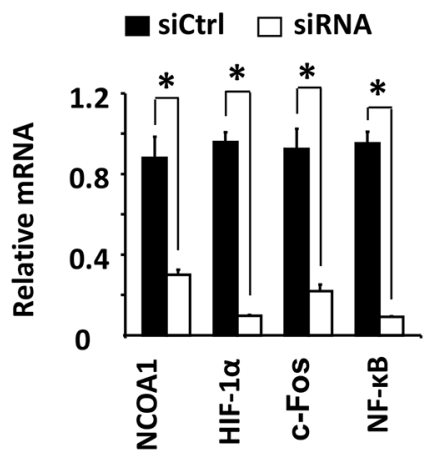

d

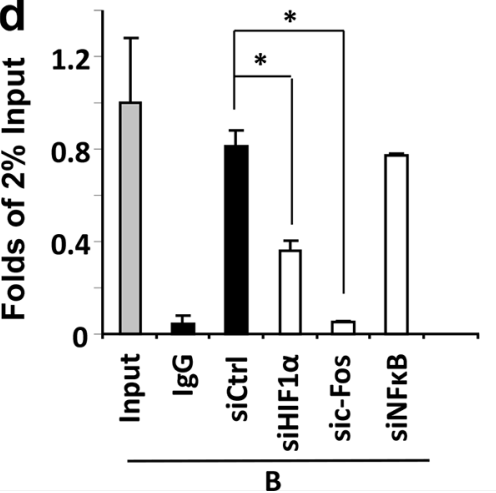

e

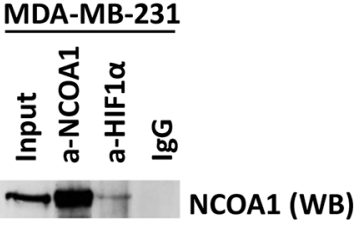

Figure 4: NCOA1 is recruited to the VEGFa promoter by HIF1 $\alpha$ and c-Fos. a. The $V E G F a$ promoter region contains a TATA box and one HIF1a, three AP-1 and one NF-kB binding sites that are known to regulate $V E G F a$ expression. Regions A-D were used for PCR amplification in ChIP assays. b. ChIP assays performed in MDA-MB-231 cells transfected with the non-targeting siRNA Smart Pool (siCtrl) or siRNA Smart Pools targeting NCOA1, HIFl $\alpha, c-F$ os or NF- $\kappa B$ mRNAs as indicated. NCOA1, HIF1 $\alpha$, c-Fos and NF- $\mathrm{kB}$ antibodies were used for ChIP and normal IgG was used as negative control for ChIP. DNA obtained from ChIP was used as template for QPCR to measure the relative DNA amounts of regions A-D of the VEGFa promoter. The QPCR results for these regions were normalized to the QPCR results of 2\% input DNA. c. The relative levels of HIF1 $\alpha, c$-Fos and $N F-\kappa B$ mRNAs in MDA-MB-231 cells transfected with non-targeting siRNA Smart Pool (siCtrl) or siRNAs targeting NCOA1, HIFl $\alpha, c-F o s$ and NF- $\kappa B$ mRNAs were measured by QPCR. d. ChIP assays for NCOA1-associated Region B of the VEGFa promoter in MDA-MB-231 cells with knockdown of HIF1 $\alpha$, c-Fos or NF-kB. Experiments in all panels were repeated at least three times. The * in all panels indicates $p<0.05$ by Student's $t$ test. e. Co-immunoprecipitation (Co-IP) assay for protein-protein interaction between NCOA1 and HIF $1 \alpha$. Cell lysate was prepared from MDAMB-231 cells. Co-IP was performed with NCOA1 antibody, HIF1 $\alpha$ antibody or non-immune IgG as negative control. The cell lysate for Co-IP (Input) and immunoprecipitated samples were analyzed by Western blotting (WB) using NCOA1 antibody.

reporter (Figure 5b). Conversely, knockdown of HIF1 $\alpha$ or c-Fos in HeLa cells significantly reduced NCOA1-promoted activity of VP-Luc reporter (Figure 5c). We also noticed that coexpression of NCOA1 with HIF1 1 , c-Fos and c-Jun in HeLa cells only slightly increased the activity of VP-Luc reporter when compared with co-expression of NCOA1 with HIF $1 \alpha$ alone or with c-Fos and c-Jun (Figure 5d). This might be attributed to the limited availability of other factors required for further activating the reporter when NCOA1, HIF $1 \alpha$, c-Fos and c-Jun were all overexpressed in these cells. Together, these results strongly support the notion that NCOA1 serves as a coactivator for HIF $1 \alpha$ and c-Fos to enhance the promoter activity of the $V E G F a$ gene.

There are two AP-1 sites and one HIF $1 \alpha$-binding element in Region B of the $V E G F a$ promoter (Figure $4 \mathrm{a}$ and Figure 5a). To examine which AP-1 site is required for NCOA1-enhanced and c-Jun/c-Fos-mediated activation of the $V E G F a$ promoter, we constructed MA1-Luc reporter with the deletion of the first AP-1 site at bp -1088, MA2Luc reporter with the deletion of the second AP-1 site at bp -938, and MA1A2-Luc reporter with the deletion of both sites. Co-expression of NCOA1, c-Jun and c-Fos in HeLa 
a

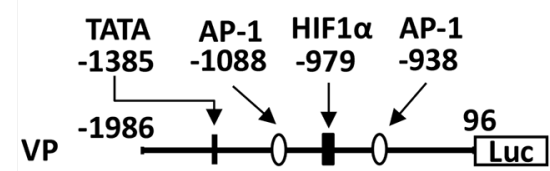

MA1 — $\longrightarrow$ LUC

MA2

MA1A2

MH1

MA2H1
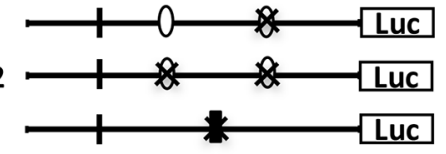

d

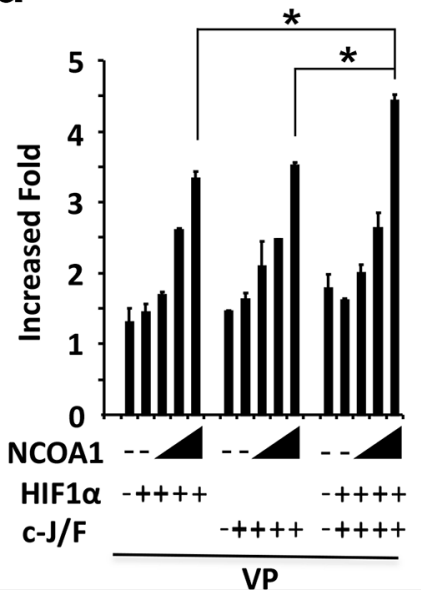

b

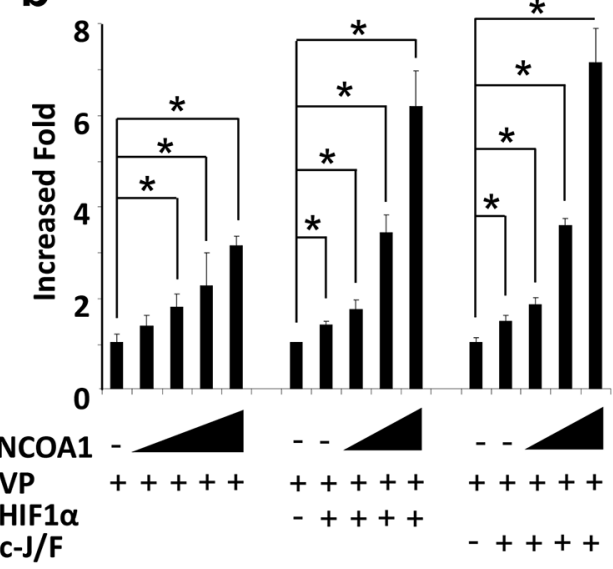

C

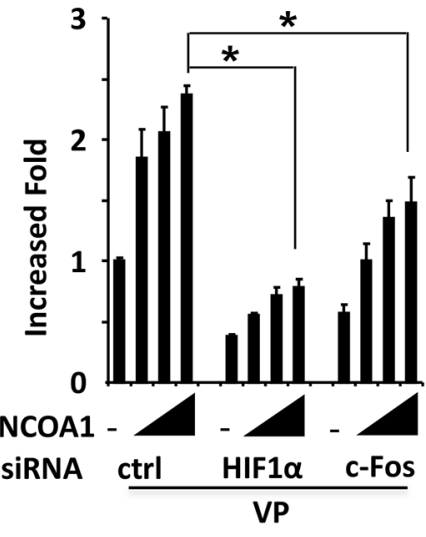

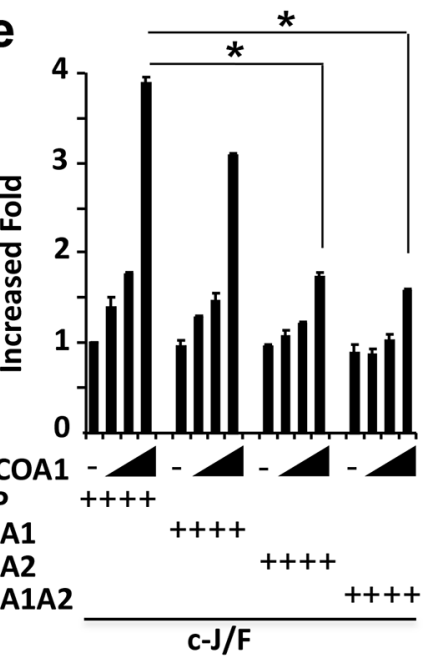
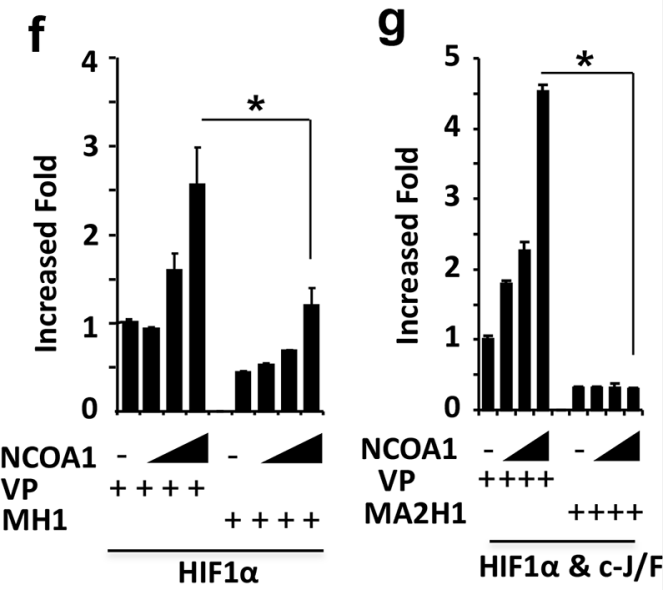

Figure 5: NCOA1 cooperates with HIF1 $\alpha$ and AP-1 to activate the VEGFa promoter. a. Wild type and mutant $V E G F a$ promoter-reporter constructs. The locations are labeled by setting the transcriptional starting site as bp 1. TATA box and AP-1 and HIF $1 \alpha$ binding sites are indicated. VP, wild type VEGFa promoter; MA1 or MA2, mutant $V E G F a$ promoters with deletion of the first or second AP-1 site; MA1A2, mutant $V E G F a$ promoter with deletion of both AP-1 sites; MH1, mutant VEGFa promoter with deletion of the HIF1 $\alpha$ binding site; MA2H1, mutant $V E G F a$ promoter with deletion of the HIF1 $\alpha$ and the second AP-1 binding sites; Luc, luciferase. b. Enhancement of $V E G F a$ promoter activity by NCOA1 alone or NCOA1 with HIF $1 \alpha$ or c-Jun/c-Fos (c-J/F). HeLa cells in 24-well plates were co-transfected with $200 \mathrm{ng}$ of VP-Luc plasmid and 0,150,300, 600, 900 or $1200 \mathrm{ng}$ of NCOA1 expression plasmid (left panel) or 0, 0, 150,300 and 600 ng of NCOA1 expression plasmid with $100 \mathrm{ng}$ of HIF $1 \alpha$ expression plasmid (middle panel) or c-J/F (50 ng each, right panel) expression plasmids as indicated. c. Knockdown of HIF1 $\alpha$ or c-Fos reduced NCOA1-promoted activity of the VEGFa promoter. HeLa cells were transfected with 0, 150,300 and $600 \mathrm{ng}$ of NCOA1 expression plasmid and $200 \mathrm{ng}$ of VP-Luc reporter plasmid. d. NCOA1 promotes HIF $1 \alpha$ and c-J/F mediated activation of the $V E G F \alpha$ promoter. HeLa cells were co-transfected with VP-Luc reporter, NCOA1 and HIF $1 \alpha$, c-Jun/cFos or both HIF $1 \alpha$ and c-Jun/c-Fos as described above for panel c. e-f. Deletion of the second AP-1 site or the HIF $1 \alpha$ binding site reduced NCOA1/C-J/F or NCOA1/HIF $1 \alpha$-promoted activity of the $V E G F a$ promoter. HeLa cells in 24-well plates were co-transfected with same amounts of NCOA1 plasmid as that in panel c, $100 \mathrm{ng}$ of c-J/F plasmids or HIF1 $\alpha$ plasmid, and $200 \mathrm{ng}$ of VP-Luc, MA1-Luc, MA2-Luc or MA1A2-Luc reporter plasmid as indicated. g. Deletion of both the second AP-1 and the HIF $1 \alpha$ binding sites diminishes NCOA1-enhanced HIF $1 \alpha$ and C-J/F-mediated activation of the VEGFa promoter. HeLa cells were transfected with the indicated plasmids as described above for panel $\mathbf{f}$. In all experiments, luciferase activity was assayed 48 hours after transfection and normalized to the total protein amount assayed for each sample. All experiments were repeated at least three times. The * in all panels indicates $p<0.05$ by One-Way ANOVA test.

cells comparably activated VP-Luc and MA1-Luc reporters, while this co-expression only slightly activated MA2-Luc and MA1A2-Luc reporters in HeLa cells (Figure 5e). These results suggest that the second AP-1 site is required for NCOA1, c-Jun and c-Fos to activate the VEGFa promoter.

To examine whether the HIF1 $\alpha$-binding element in Region $\mathrm{B}$ of the $V E G F a$ promoter is required for
NCOA1-promoted and HIF $1 \alpha$-mediated activation of the $V E G F a$ promoter, we constructed MH1-Luc reporter in which the HIF $1 \alpha$-binding element at bp -979 was deleted (Figure 5a). Co-expression of NCOA1 and HIF $1 \alpha$ in HeLa cells robustly increased the activity of the VA-Luc wild type reporter, but only slightly increased the MH1-Luc mutant reporter (Figure 5f). These results demonstrate that the 

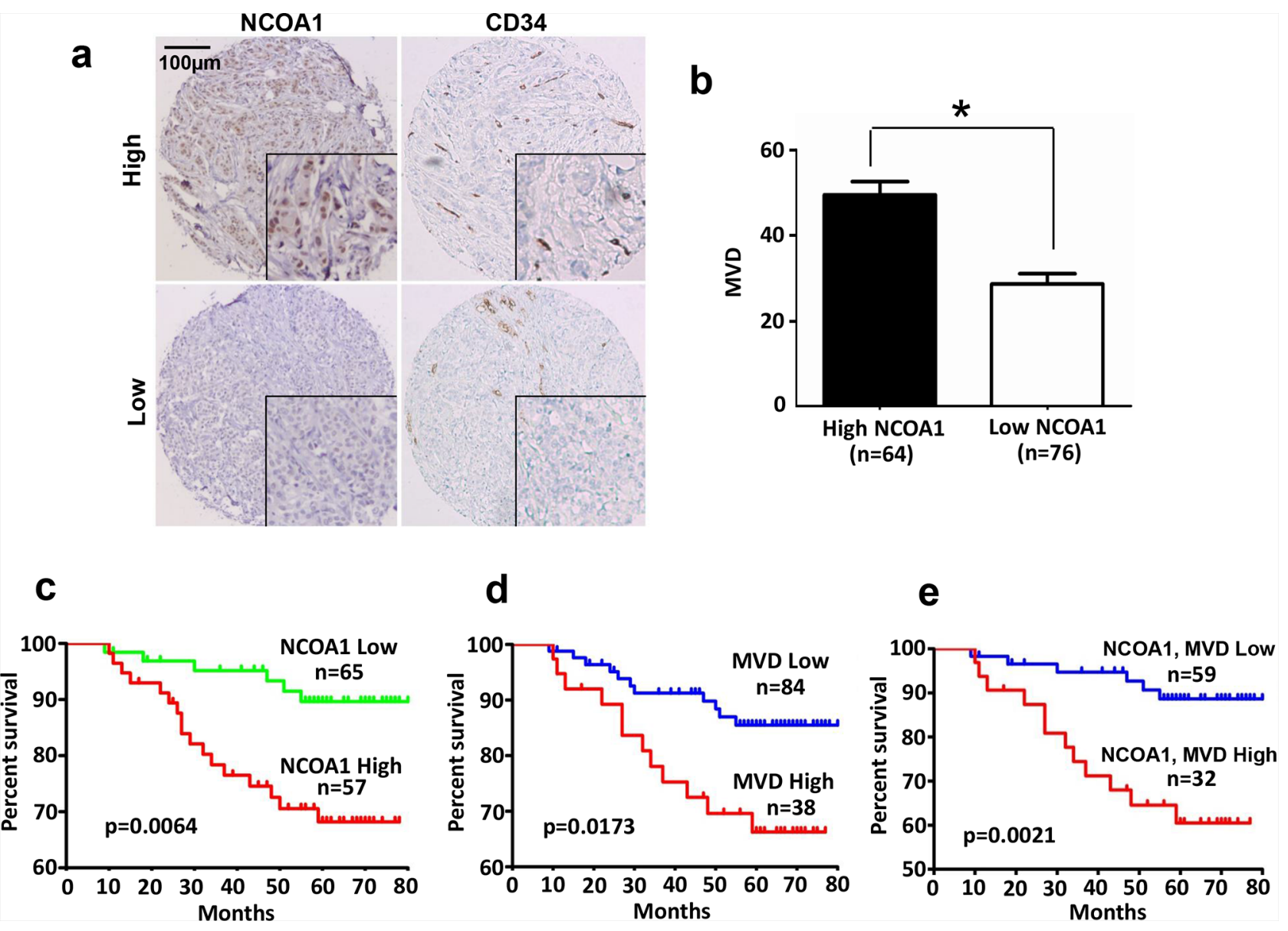

Figure 6: NCOA1 protein expression and its correlations with human breast tumor microvascular density (MVD) and patient survival. a. Representative images of high and low immunoreactivities of NCOA1 and CD34 in breast tumor sections. Images were taken at the magnification of $200 \times$. b. Semi-quantitative analysis of MVD in breast tumor tissues with high NCOA1 (immunoreactivity score $\geq 3$ ) and low NCOA1 (immunoreactivity score $<3$ ) protein expression. Data are presented as Mean \pm SD microvessels per 200× viewing field. ${ }^{*} P<0.05$ by Chi-square test. $\mathbf{c}-\mathbf{d}$. The Kaplan Meier survival curves of breast cancer patients with high versus low NCOA1 protein expression (panel c), with high MVD $(>40)$ versus low MVD $(\leq 40)$ (panel d), and with both high NCOA1 and high MVD versus both low NCOA1 and MVD (panel e). The indicated $p$ values were calculated by Logrank test. $n$, number of patients.

HIF $1 \alpha$-binding element in Region B is required for NCOA 1 and HIF $1 \alpha$-induced activation of the VEGFa promoter.

Furthermore, deletion of both the HIF1 $\alpha$-binding element at bp -979 and the second AP-1 site at bp -938 in Region B completely abolished NCOA1, HIF $1 \alpha$ and c-Jun/c-Fos promoted activation of the VEGFa promoter in HeLa cells (Figure 5a and 5g). These results indicate that NCOA1 works with both HIF1a and c-Jun/c-Fos to activate the $V E G F a$ promoter.

\section{NCOA1 expression positively correlates with MVD in human breast tumors and poor patient survival}

Analysis of the RNA profiling data set obtained from a cohort of 270 human breast tumors, which was deposited in Oncomine Database by Bittner et al., revealed that the levels of NCOA1 mRNA expression positively correlated with both expression levels of $V E G F a$ mRNA $(r=0.23, P<0.001)$ and CD31 mRNA $(r=0.40, P<0.001)$ (Supplementary Figure S2). This is consistent with the role of NCOA1 in upregulating VEGFa to stimulate angiogenesis in human breast tumors. To validate this important role of NCOA1, we performed semi-quantitative immunohistochemistry (IHC) for NCOA1 in the tumor cells and CD34 in the vascular endothelial cells of small blood vessels in 140 human breast tumors. NCOA1 protein was mainly detected in the nuclei of breast cancer cells at different immunostaining intensities in different tumor sections. About 45\% (64/140) and 55\% (76/140) of breast tumors exhibited high (immunoreactivity score $\geq 3$ ) and low (immunoreactivity score $<3$ ) NCOA1 immunoreactivity. CD34 was detected in endothelial cells at similar immunostaining intensity, but different MVDs indicated by the CD34-positive cells were observed in different tumors (Figure 6a). We found that MVD in breast tumors expressing higher NCOA1 protein is significantly higher than that in breast tumors expressing lower NCOA1 protein (Figure 6b). These results confirmed that high 
NCOA1 expression is positively associated with high MVD in human breast tumors.

Kaplan-Meier survival curves were calculated for patient groups with high and low NCOA1 protein expression and MVD according to their long timefollowing up data. Patients with high NCOA1 protein or high MVD showed significantly worse overall survival rates versus patients with low NCOA1 protein or low MVD (Figure 6c and 6d). Patients with both high NCOA1 protein and high MVD showed the worst overall survival rate when compared with patients with both low NCOA1 protein and low MVD (Figure 6e). These results indicate that high NCOA1 expression concomitant with high MVD in breast tumors are associated with poor prognosis.

\section{DISCUSSION}

In this study, we discovered that Ncoa1 protein levels are positively associated with the densities of small blood vessels in several models of mouse mammary tumors induced by PyMT or Neu (HER2) expression. Furthermore, we demonstrated that knockout of Ncoal in mouse mammary tumor cells or knockdown of NCOA1 in human breast cancer cells largely compromised their capabilities to induce angiogenesis in vivo. Moreover, we found that higher NCOA1 protein in human breast tumors is also positively associated with higher densities of small blood vessels. Patients with both high NCOA1 and high MVD exhibit the worst prognosis versus patients with low NCOA1, low MVD, and both low NCOA1 and low MVD. These observations indicate that NCOA1 plays an important role in breast cancer progression through promoting breast tumor angiogenesis. Tumor vascular density has been suggested as a clinical parameter for predicting recurrence and deciding treatment strategies [43]. In comparison with normal blood vessels, the tumor vessels are more tortuous and disordered, lack the clear hierarchy of arterioles, capillaries and venules, and have loose connections among endothelial cells, pericytes and basement membrane [44]. Since these features of tumor vessels facilitate the intravasation of tumor cells for metastasis, high vascular density (MVD) in tumors usually predicts worse outcomes in cancer patients [45]. Consistently, we have previously shown that NCOA1 overexpression in the mouse mammary tumor cells significantly promoted lung metastasis [19], while knockout of Ncoal in the mouse tumor cells drastically inhibited lung metastasis [20]. Similarly, breast tumors with high NCOA1 protein also showed poor prognosis (Figure 6c) [18, 46]. Therefore, NCOA1 overexpression-induced angiogenesis in breast tumors may directly contribute to breast cancer progression and metastasis.

Tumors induce angiogenesis by secreting various growth factors, and VEGFa is the most important one of such growth factors $[47,48]$. In this study, we have identified $V E G F a$ as a direct target gene of NCOA1 by multiple lines of evidence. First, we showed that the compromised ability of Ncoa1 null mammary tumor cells to induce in vivo angiogenesis can be rescued by VEGFa treatment, suggesting a reduced secretion of VEGFa from Ncoa1 null cells. Furthermore, we demonstrated that VEGFa expression in and secretion from breast tumor cells are positively associated with the manipulated NCOA1 expression levels, suggesting that $\mathrm{NCOA} 1$ tightly regulates $V E G F a$ expression in these tumor cells. Moreover, NCOA1 is recruited to the $V E G F a$ promoter by associating with HIF $1 \alpha$ and c-Fos in breast cancer cells. Finally, we showed that NCOA1 potentiates the transcriptional activity of the $V E G F a$ promoter by serving as a coactivator for both HIF $1 \alpha$ and c-Fos/c-Jun that bind to the HIF1 $\alpha$ binding site at bp -979 and the AP-1 site at bp -938 of the VEGFa promoter. Together, these findings indicate that the angiogenic function of NCOA1 in breast tumor is mediated, in part, by serving as a transcriptional coactivator for both HIF1 $\alpha$ and AP-1 mediated $V E G F a$ expression, since the crucial role of VEGFa in both physiological and pathological angiogenesis has been extensively studied and well documented $[26,49]$.

Although multiple transcription factors including HIF $1 \alpha$, AP-1, NF-кB, Sp1 and ER $\alpha$ have been reported to regulate VEGFa expression [38-40, 50, 51], our study is the first to show NCOA1, a transcriptional coactivator, can robustly and simultaneously coactivate two transcription factors, HIF $1 \alpha$ and AP-1, to augment $V E G F a$ expression and breast tumor angiogenesis. Our data showed that preventing either HIF $1 \alpha$ or AP-1 from binding to the VEGFa promoter partially reduced NCOA1-promoted transcriptional activity of this promoter, while preventing both HIF $1 \alpha$ and AP-1 from binding to the $V E G F a$ promoter completely abolished NCOA1-promoted transcriptional activity of this promoter. This strongly supports that NCOA1 works with both HIF $1 \alpha$ and AP-1 to upregulate $V E G F a$ expression. On the other hand, co-expression of both HIF $1 \alpha$ and AP-1 only slightly increased NCOA1-promoted transcriptional activity of the $V E G F a$ promoter when compared with only expression of either HIF $1 \alpha$ or AP-1, suggesting that other factors required for VEGFa transcription might become limited when HIF $1 \alpha$, AP-1 and NCOA1 are all overexpressed in the cell. Alternatively, considering there are only 23 base pairs of nucleotides interval between HIF $1 \alpha$ and AP-1 binding sites in the promoter, the occupation of one site by either transcription factor might reduce the occupation of the other adjacent site by the other transcription factor. HIF $1 \alpha$ in tumor cells is induced and activated under hypoxia condition, while AP-1 functions under both normoxia and hypoxia conditions. This explains why NCOA1 could enhance the transcriptional activity of the $V E G F a$ promoter under both hypoxia and normoxia conditions and also implies a role of NCOA1 in upregulating $V E G F a$ expression and tumor angiogenesis under both conditions.

NCOA1 works not only with both HIF $1 \alpha$ and AP-1 to upregulate VEGFa expression as shown in this study but also works with different transcription factors to upregulate different target genes to promote breast cancer progression 
and metastasis as reported previously $[19,21,22]$. We have previously shown that NCOA1 interacts with PEA3 or AP-1 to upregulate the expression of Twist or integrin $\alpha 5$ and CSF-1. These target gene products further potentiate, either directly or indirectly, EMT, migration, invasion and/or metastasis of breast cancer cells [19, 21, 22]. These findings provide a possibility to use NCOA1 as a molecular target for inhibiting its multiple target gene-mediated pathways that drive breast cancer progression and metastasis. Especially, Ncoa1 knockout mice grow well and show a normal life span [35], supporting the notion that NCOA1 may be a preferential cancer target with tolerable adverse effect. Recently, gossypol and bufalin have been identified as specific small molecular inhibitors for both NCOA1 and NCOA3 and have been shown to inhibit breast cancer cell growth and/or metastasis in culture and/or mice $[52,53]$. These translational studies suggest that targeting these overexpressed coactivators like NCOA1 and NCOA3 is indeed a feasible approach to control breast cancer growth and/or metastasis.

It is well established that tumor growth requires angiogenesis for supplying oxygen and nutrients [24]. However, we found that although NCOA1 promotes angiogenesis in breast tumors, overexpression or knockout of Ncoal in mice does not significantly affect mammary tumor growth $[19,20]$. Although the underlying mechanisms are currently unknown, several possibilities may be speculated. First, we found that although Tg(MMTV-TVA/ RCAS-PyMT) tumors grow much faster than Tg(MMTVNeu) and Tg(MMTV-PyMT) tumors [19, 20], MVD in Tg(MMTV-TVA/RCAS-PyMT) tumors is actually much lower than MVD in the other two types of tumors (Figure 1b). These findings suggest that the growth of different types of tumors may have different requirements on their MVDs. It is possible that breast tumor cells with different levels of Ncoal expression also have different requirements on MVD for growth. Furthermore, the changes of other Ncoa1 functions independent of its angiogenic function caused by the changed Ncoa1 expression levels may counter-regulate the growth effects of angiogenesis in breast tumors. For example, knockout of Ncoal influences fat oxidation and energy metabolism $[54,55]$, which may complicate the correlation relationship between Ncoal-promoted tumor angiogenesis and Ncoa1-influenced tumor growth.

\section{MATERIALS AND METHODS}

\section{Breast cancer mouse models and cell culture}

The original Tg(MMTV-PyMT), Tg(MMTV-TVA/ RCAS-PyMT), Tg(MMTV-Neu), Tg(MMTV-NCOA1) and $\mathrm{Ncoal}^{-/-}$mouse lines were described previously [19, 34-37]. The Tg(MMTV-PyMT), Tg(MMTV-PyMT) $\times$ Ncoal $^{-/-}$, Tg(MMTV-TVA/RCAS-PyMT), Tg(MMTVTVA/RCAS-PyMT) $\times$ Tg(MMTV-NCOA1), Tg(MMTV$\mathrm{Neu})$ and $\mathrm{Tg}(\mathrm{MMTV}-\mathrm{Neu}) \times \mathrm{Tg}(\mathrm{MMTV}-\mathrm{NCOA} 1)$ mice used in this study were produced as described previously
$[19,20]$. The MMTV-PyMT mouse mammary tumor cell lines with Ncoa1 expression including W1 and W2 cell lines and with Ncoal knockout including K1 and $\mathrm{K} 2$ cell lines were developed from mammary tumors in Tg(MMTV-PyMT) and Tg(MMTV-PyMT) $\times \mathrm{Ncoal}^{-/-}$ mice and cultured as described previously [21]. MDAMB-231 human breast cancer cells and HeLa cells were cultured in DMEM containing 10\% FBS.

\section{Mouse mammary tumor collection, processing and immunohistochemistry}

Mammary tumors were isolated from $\mathrm{Tg}(\mathrm{MMTV}$ PyMT) and Tg(MMTV-PyMT) $\times$ Ncoal $^{-/-}$mice at week 8 and week 13 after their palpable tumors were detected, from Tg(MMTV-TVA/RCAS-PyMT) and Tg(MMTV-TVA/RCASPyMT $) \times \operatorname{Tg}($ MMTV-NCOA1 $)$ mice at week 13 after their palpable tumors were detected, and from Tg(MMTV-Neu) and $\mathrm{Tg}(\mathrm{MMTV}-\mathrm{Neu}) \times \mathrm{Tg}(\mathrm{MMTV}-\mathrm{NCOA} 1)$ mice at week 2 and week 9 after their palpable tumors were detected. The mammary tumor tissues were fixed in $4 \%$ paraformaldehyde (PFA) in phosphate-buffered saline (PBS), dehydrated in ethanol solution series and embedded in paraffin blocks. Tissue sections were prepared and immunohistochemistry was performed with FLK and CD31 antibodies (ab 28364, Abcam, 1:200 dilution used) as described $[13,21]$.

\section{Knockdown and adenovirus-mediated expression of NCOA1}

Lentiviral particles for expressing non-targeting control shRNA (shCtrl) and NCOA1 mRNA-targeting shRNAs including shNCOA1-1 (sh1) and shNCOA1-2 (sh2) were obtained from the Cell-Based Assay Screening Core at Baylor College of Medicine and used to infect MDAMB-231 cells as described previously [22]. The infected cells were selected in the medium containing $1 \mu \mathrm{g} / \mathrm{ml}$ puromycin for 14 days to establish stable NCOA1-knockdown cells for experiments. To knock down mouse Ncoa1, the W1 and W2 cells were transiently transfected with siRNA Smart Pool that targets mouse Ncoa1 mRNA (Dharmacon, Inc. Lafayette, $\mathrm{CO})$. The same cells transfected with a non-targeting siRNA pool were used as controls. Adenoviruses containing a GFP or a NCOA1 expression cassette were used to infect the K1 and $\mathrm{K} 2$ cells for expressing GFP as a control or NCOA1 as described previously $[13,56]$.

\section{Reporter construction and luciferase assay}

The 5' regulatory DNA fragment from bp -1987 to 96 of the human VEGFa gene was amplified by high-fidelity PCR using specific primers (Supplementary Table S1) and subcloned into the pGL3 basic vector with a luciferase reporter (Promega, Inc. Madison, WI). Mutant promoter-reporter plasmids with deleted HIF1 $\alpha$-binding site at bp -979 and/or AP-1-binding sites at bp -1088 and bp -938 were constructed 
by using the similar approaches as described previously [19]. HeLa cells were cultured in 6-well plates and transfected with $200 \mathrm{ng} /$ well of the promoter-reporter plasmid, $100 \mathrm{ng} /$ well of the HIF $1 \alpha$, NF- $\mathrm{KB}$, or c-Jun and c-Fos expression plasmids and different amounts of NCOA1 expression plasmid as described previously [19]. Luciferase activity was also assayed as described previously [19]. In HIF $1 \alpha$-transfected cells, $\mathrm{CoCl}_{2}$ was added to $100 \mu \mathrm{M}$ in the medium to create a hypoxia condition as described previously [57].

\section{In vivo matrigel angiogenesis assay}

Experiment was performed as described previously [58]. Briefly, $150 \mu \mathrm{l}$ of Matrigel (BD Biosciences, San Jose, CA) was subcutaneously injected to the back of 5-6-weekold female SCID/beige mice to form plugs. Then, $1 \times 10^{5}$ of mouse mammary tumor or human breast cancer cells were injected into the central region of the Matrigel plugs. After the injected mice were maintained for 8 days, the Matrigel plugs were isolated for imaging. The imaged Matrigel plugs were fixed in 2\% PFA, washed with PBS, and frozen in OCT at $-80^{\circ} \mathrm{C}$. Cryosections were prepared from the frozen samples and these sections were processed for immunofluorescent staining using CD31 and Flk1 antibodies.

\section{ELISA}

The concentration of VEGFa protein was measured using human VEGFa ELISA kit (Invitrogen, Grand Island, NY) by following the manufacturer's instructions. Twenty $\mu \mathrm{l}$ of medium (DMEM containing $0.5 \%$ FBS) conditioned by MDA-MB-231 cells expressing non-targeting shRNA or NCOA1 shRNA for 48 hours was used for each measurement.

\section{ChIP assay}

ChIP assays were performed as described previously $[21,22]$. Briefly, MDA-MB-231 cells with and without knockdown of NCOA1, HIF1 $\alpha$, c-Fos or NF- $\kappa$ B were fixed in $1 \%$ formaldehyde for 10 minutes. DNA-protein complexes extracted from these fixed cells were subjected to immunoprecipitation with NCOA1, HIF1 $\alpha$, c-Fos or $\mathrm{NF}-\kappa \mathrm{B}$ antibodies. Immunoprecipitated DNA was eluted and subjected to QPCR analysis using specific primer pairs (Supplementary Table S1) that amplify different promoter regions indicated in Figure 4. In negative control ChIP assays, equal amount of normal IgG was used to replace specific antibodies. Each experiment was repeated at least three times.

\section{Microvascular density determination}

Microvascular density was determined as described previously [59]. In brief, blood vessels were visualized by CD31 or CD34 immunohistochemistry or immunofluorescence in the tissue sections prepared from mouse and human breast tumors and Matrigel plugs with angiogenesis. Tumor areas within the "hot spots" regions, which contain greatest vessel density, were imaged under a microscope at $200 \times$ magnification. Tumor areas associated with ulceration or granulation were excluded from consideration as the "hot spot". Any stained endothelial cell was counted to represent a single vessel if it was clearly separated from adjacent microvessels and other connective tissue elements. Two independent scientists performed the vessel density evaluation and the average was regarded as the final microvessel count.

\section{Breast cancer patients and tissue microarray}

A total of 140 human breast tumor specimens were collected from primary surgeries before any endocrine therapy was given during 2006-2008 at Southwest Hospital of Third Military Medical University in China. 122 patients were followed up by clinic interviews for 9-80 months. Patient demographic and pathohistologic data including age, tumor size and grade, lymph node metastasis, recurrence and survival time, estrogen and progesterone receptor expression, as well as HER2 expression were retrieved from clinical records. Tumor specimens embedded in the paraffin blocks were used for constructing tissue microarrays as described [13]. Immunohistochemistry using NCOA1 and CD34 antibodies was performed as described previously [13]. The immunostaining intensity for NCOA1 was independently scored by two pathologists according to the Allred scoring system [60] and the average score for each sample was regarded as the final score. MVD in tumors visualized by CD34 immunostaining was determined as described above. Pearson Chi-square test was used for categorical variables to compare two proportions. Kaplan Meier estimates of survival functions were computed and Logrank test was applied to compare the difference of survival. $P<0.05$ was considered to be statistically significant. This study was approved by the Ethics Committee of Southwest Hospital of Third Military Medical University, and written informed consents were obtained from all patients prior to treatment.

\section{Other methods}

QPCR, Western blotting and Co-immunoprecipitation were performed as described previously [21, 22]. Primer and universal probe sequences for QPCR were provided in Supplementary Table S1.

\section{ACKNOWLEDGMENTS AND FUNDING}

We thank Hongwu Chen for providing Ad-NCOA1, Dong-Kee Lee and Zhen Feng for experimental assistance, and Jarrod Martinez for proofreading the manuscript. This work was partially supported by NIH grant CA112403, Cancer Prevention and Research Institute of Texas (CPRIT) grants 
RP120732-P5 and RP150197, and a subproject of the Susan G. Komen Foundation Promise Grant (PG12221410) to J. Xu. This work was also partially supported by National Natural Science Foundation of China (81472482) and Natural Science Foundation Project of CQ CSTC (cstc2013jcyjA10116) to Y. $\mathrm{Xu}$. The work done by J. Wang was supported by CPRIT (R1104) and Welch Foundation (Q-1798).

\section{CONFLICTS OF INTEREST}

The authors have no conflicting financial interests.

\section{REFERENCES}

1. Onate SA, Tsai SY, Tsai MJ, O'Malley BW. Sequence and characterization of a coactivator for the steroid hormone receptor superfamily. Science. 1995; 270:1354-1357.

2. Xu J, Wu RC, O'Malley BW. Normal and cancer-related functions of the p160 steroid receptor co-activator (SRC) family. Nature reviews Cancer. 2009; 9:615-630.

3. Chen H, Lin RJ, Xie W, Wilpitz D, Evans RM. Regulation of hormone-induced histone hyperacetylation and gene activation via acetylation of an acetylase. Cell. 1999; 98:675-686.

4. Feng Q, Yi P, Wong J, O’Malley BW. Signaling within a coactivator complex: methylation of SRC-3/AIB1 is a molecular switch for complex disassembly. Molecular and cellular biology. 2006; 26:7846-7857.

5. Naeem H, Cheng D, Zhao Q, Underhill C, Tini M, Bedford MT, Torchia J. The activity and stability of the transcriptional coactivator $\mathrm{p} / \mathrm{CIP} / \mathrm{SRC}-3$ are regulated by CARM1-dependent methylation. Molecular and cellular biology. 2007; 27:120-134.

6. Anzick SL, Kononen J, Walker RL, Azorsa DO, Tanner MM, Guan XY, Sauter G, Kallioniemi OP, Trent JM, Meltzer PS. AIB1, a steroid receptor coactivator amplified in breast and ovarian cancer. Science. 1997; 277:965-968.

7. Tien JC, Liu Z, Liao L, Wang F, Xu Y, Wu YL, Zhou N, Ittmann $\mathrm{M}, \mathrm{Xu}$ J. The steroid receptor coactivator-3 is required for the development of castration-resistant prostate cancer. Cancer research. 2013; 73:3997-4008.

8. Tien JC, Liao L, Liu Y, Liu Z, Lee DK, Wang F, Xu J. The steroid receptor coactivator-3 is required for developing neuroendocrine tumor in the mouse prostate. International Journal of Biological Sciences. 2014; 10:1116-1127.

9. Osborne CK, Bardou V, Hopp TA, Chamness GC, Hilsenbeck SG, Fuqua SA, Wong J, Allred DC, Clark GM, Schiff R. Role of the estrogen receptor coactivator AIB1 (SRC-3) and HER-2/neu in tamoxifen resistance in breast cancer. Journal of the National Cancer Institute. 2003; 95:353-361.

10. Fereshteh MP, Tilli MT, Kim SE, Xu J, O’Malley BW, Wellstein A, Furth PA, Riegel AT. The nuclear receptor coactivator amplified in breast cancer-1 is required for Neu
(ErbB2/HER2) activation, signaling, and mammary tumorigenesis in mice. Cancer research. 2008; 68:3697-3706.

11. Kuang SQ, Liao L, Wang S, Medina D, O’Malley BW, $\mathrm{Xu}$ J. Mice lacking the amplified in breast cancer 1/steroid receptor coactivator-3 are resistant to chemical carcinogeninduced mammary tumorigenesis. Cancer research. 2005; 65:7993-8002.

12. Torres-Arzayus MI, Font de Mora J, Yuan J, Vazquez F, Bronson R, Rue M, Sellers WR, Brown M. High tumor incidence and activation of the PI3K/AKT pathway in transgenic mice define AIB1 as an oncogene. Cancer cell. 2004; $6: 263-274$.

13. Qin L, Liao L, Redmond A, Young L, Yuan Y, Chen H, O'Malley BW, Xu J. The AIB1 oncogene promotes breast cancer metastasis by activation of PEA3-mediated matrix metalloproteinase 2 (MMP2) and MMP9 expression. Molecular and cellular biology. 2008; 28:5937-5950.

14. Wu MY, Fu J, Xu J, O’Malley BW, Wu RC. Steroid receptor coactivator 3 regulates autophagy in breast cancer cells through macrophage migration inhibitory factor. Cell research. 2012; 22:1003-1021.

15. Long W, Foulds CE, Qin J, Liu J, Ding C, Lonard DM, Solis LM, Wistuba II, Qin J, Tsai SY, Tsai MJ, O’Malley BW. ERK3 signals through SRC-3 coactivator to promote human lung cancer cell invasion. The Journal of clinical investigation. 2012; 122:1869-1880.

16. Fleming FJ, Hill AD, McDermott EW, O’Higgins NJ, Young LS. Differential recruitment of coregulator proteins steroid receptor coactivator-1 and silencing mediator for retinoid and thyroid receptors to the estrogen receptorestrogen response element by beta-estradiol and 4-hydroxytamoxifen in human breast cancer. The Journal of clinical endocrinology and metabolism. 2004; 89:375-383.

17. Fleming FJ, Myers E, Kelly G, Crotty TB, McDermott EW, O'Higgins NJ, Hill AD, Young LS. Expression of SRC1, AIB1, and PEA3 in HER2 mediated endocrine resistant breast cancer; a predictive role for SRC-1. Journal of clinical pathology. 2004; 57:1069-1074.

18. Walsh CA, Qin L, Tien JC, Young LS, Xu J. The function of steroid receptor coactivator-1 in normal tissues and cancer. International Journal of Biological Sciences. 2012; 8:470-485.

19. Qin L, Wu YL, Toneff MJ, Li D, Liao L, Gao X, Bane FT, Tien JC, Xu Y, Feng Z, Yang Z, Theissen SM, Li Y, Young L, Xu J. NCOA1 Directly Targets M-CSF1 Expression to Promote Breast Cancer Metastasis. Cancer research. 2014; 74:3477-3488.

20. Wang S, Yuan Y, Liao L, Kuang SQ, Tien JC, O’Malley $\mathrm{BW}, \mathrm{Xu}$ J. Disruption of the SRC-1 gene in mice suppresses breast cancer metastasis without affecting primary tumor formation. Proceedings of the National Academy of Sciences of the United States of America. 2009; 106:151-156.

21. Qin L, Liu Z, Chen $\mathrm{H}, \mathrm{Xu}$ J. The steroid receptor coactivator-1 regulates twist expression and promotes breast cancer metastasis. Cancer research. 2009; 69:3819-3827. 
22. Qin L, Chen X, Wu Y, Feng Z, He T, Wang L, Liao L, $\mathrm{Xu}$ J. Steroid receptor coactivator-1 upregulates integrin alpha(5) expression to promote breast cancer cell adhesion and migration. Cancer research. 2011; 71:1742-1751.

23. Kishimoto H, Wang Z, Bhat-Nakshatri P, Chang D, Clarke R, Nakshatri H. The p160 family coactivators regulate breast cancer cell proliferation and invasion through autocrine/paracrine activity of SDF-1alpha/CXCL12. Carcinogenesis. 2005; 26:1706-1715.

24. Folkman J. Tumor angiogenesis: therapeutic implications. The New England journal of medicine. 1971; 285:1182-1186.

25. Ribatti D, Vacca A, Dammacco F. The role of the vascular phase in solid tumor growth: a historical review. Neoplasia. 1999; 1:293-302.

26. Bouis D, Kusumanto Y, Meijer C, Mulder NH, Hospers GA. A review on pro- and anti-angiogenic factors as targets of clinical intervention. Pharmacological research: the official journal of the Italian Pharmacological Society. 2006; 53:89-103.

27. Ferrara N, Gerber HP, LeCouter J. The biology of VEGF and its receptors. Nature medicine. 2003; 9:669-676.

28. Ellis LM, Hicklin DJ. VEGF-targeted therapy: mechanisms of anti-tumour activity. Nature reviews Cancer. 2008; 8:579-591.

29. Gimbrone MA Jr, Leapman SB, Cotran RS, Folkman J. Tumor angiogenesis: iris neovascularization at a distance from experimental intraocular tumors. Journal of the National Cancer Institute. 1973; 50:219-228.

30. Rafii S, Lyden D, Benezra R, Hattori K, Heissig B. Vascular and haematopoietic stem cells: novel targets for anti-angio genesis therapy?. Nature reviews Cancer. 2002; 2:826-835.

31. Kaplan RN, Riba RD, Zacharoulis S, Bramley AH, Vincent L, Costa C, MacDonald DD, Jin DK, Shido K, Kerns SA, Zhu Z, Hicklin D, Wu Y, Port JL, Altorki N, Port ER, et al. VEGFR1-positive haematopoietic bone marrow progenitors initiate the pre-metastatic niche. Nature. 2005; 438:820-827.

32. Shojaei F. Anti-angiogenesis therapy in cancer: current challenges and future perspectives. Cancer letters. 2012; 320:130-137.

33. Forsythe JA, Jiang BH, Iyer NV, Agani F, Leung SW, Koos RD, Semenza GL. Activation of vascular endothelial growth factor gene transcription by hypoxia-inducible factor 1. Molecular and cellular biology. 1996; 16:4604-4613.

34. Du Z, Podsypanina K, Huang S, McGrath A, Toneff MJ, Bogoslovskaia E, Zhang X, Moraes RC, Fluck M, Allred DC, Lewis MT, Varmus HE, Li Y. Introduction of oncogenes into mammary glands in vivo with an avian retroviral vector initiates and promotes carcinogenesis in mouse models. Proceedings of the National Academy of Sciences of the United States of America. 2006; 103:17396-17401.
35. Xu J, Qiu Y, DeMayo FJ, Tsai SY, Tsai MJ, O’Malley BW. Partial hormone resistance in mice with disruption of the steroid receptor coactivator-1 (SRC-1) gene. Science. 1998; 279:1922-1925.

36. Guy CT, Cardiff RD, Muller WJ. Induction of mammary tumors by expression of polyomavirus middle $\mathrm{T}$ oncogene: a transgenic mouse model for metastatic disease. Molecular and cellular biology. 1992; 12:954-961.

37. Muller WJ, Sinn E, Pattengale PK, Wallace R, Leder P. Single-step induction of mammary adenocarcinoma in transgenic mice bearing the activated c-neu oncogene. Cell. 1988; 54:105-115.

38. Yoshida S, Ono M, Shono $\mathrm{T}$, Izumi H, Ishibashi $\mathrm{T}$, Suzuki H, Kuwano M. Involvement of interleukin-8, vascular endothelial growth factor, and basic fibroblast growth factor in tumor necrosis factor alpha-dependent angiogenesis. Molecular and cellular biology. 1997; 17:4015-4023.

39. Cao Y, Linden P, Shima D, Browne F, Folkman J. In vivo angiogenic activity and hypoxia induction of heterodimers of placenta growth factor/vascular endothelial growth factor. The Journal of clinical investigation. 1996; 98:2507-2511.

40. Garrido C, Saule S, Gospodarowicz D. Transcriptional regulation of vascular endothelial growth factor gene expression in ovarian bovine granulosa cells. Growth factors. 1993; 8:109-117.

41. Lee SK, Kim HJ, Na SY, Kim TS, Choi HS, Im SY, Lee JW. Steroid receptor coactivator-1 coactivates activating protein-1-mediated transactivations through interaction with the c-Jun and c-Fos subunits. The Journal of biological chemistry. 1998; 273:16651-16654.

42. Tischer E, Mitchell R, Hartman T, Silva M, Gospodarowicz D, Fiddes JC, Abraham JA. The human gene for vascular endothelial growth factor. Multiple protein forms are encoded through alternative exon splicing. The Journal of biological chemistry. 1991; 266:11947-11954.

43. Weidner N, Semple JP, Welch WR, Folkman J. Tumor angiogenesis and metastasis - correlation in invasive breast carcinoma. The New England journal of medicine. 1991; 324:1-8.

44. Hiratsuka S. Vasculogenensis, angiogenesis and special features of tumor blood vessels. Frontiers in bioscience. 2011; 16:1413-1427.

45. Bergers G, Benjamin LE. Tumorigenesis and the angiogenic switch. Nature reviews Cancer. 2003; 3:401-410.

46. Redmond AM, Bane FT, Stafford AT, McIlroy M, Dillon MF, Crotty TB, Hill AD, Young LS. Coassociation of estrogen receptor and $\mathrm{p} 160$ proteins predicts resistance to endocrine treatment; SRC-1 is an independent predictor of breast cancer recurrence. Clinical cancer research : an official journal of the American Association for Cancer Research. 2009; 15:2098-2106. 
47. Chung AS, Ferrara N. Developmental and pathological angiogenesis. Annu Rev Cell Dev Biol. 2011; 27:563-584.

48. Leung DW, Cachianes G, Kuang WJ, Goeddel DV, Ferrara N. Vascular endothelial growth factor is a secreted angiogenic mitogen. Science. 1989; 246:1306-1309.

49. Birbrair A, Zhang T, Wang ZM, Messi ML, Olson JD, Mintz A, Delbono O. Type-2 pericytes participate in normal and tumoral angiogenesis. American Journal of PhysiologyCell Physiology. 2014; 307:C25-38.

50. Stoner M, Wormke M, Saville B, Samudio I, Qin C, Abdelrahim M, Safe S. Estrogen regulation of vascular endothelial growth factor gene expression in ZR-75 breast cancer cells through interaction of estrogen receptor alpha and SP proteins. Oncogene. 2004; 23:1052-1063.

51. Abdelrahim M, Smith R 3rd, Burghardt R, Safe S. Role of Sp proteins in regulation of vascular endothelial growth factor expression and proliferation of pancreatic cancer cells. Cancer research. 2004; 64:6740-6749.

52. Wang Y, Lonard DM, Yu Y, Chow DC, Palzkill TG, O'Malley BW. Small molecule inhibition of the steroid receptor coactivators, SRC-3 and SRC-1. Mol Endocrinol. 2011; 25:2041-2053.

53. Wang Y, Lonard DM, Yu Y, Chow DC, Palzkill TG, Wang J, Qi R, Matzuk AJ, Song X, Madoux F, Hodder P, Chase P, Griffin PR, Zhou S, Liao L, Xu J, et al. Bufalin is a potent small-molecule inhibitor of the steroid receptor coactivators SRC-3 and SRC-1. Cancer research. 2014; 74:1506-1517.
54. Stashi E, York B, O’Malley BW. Steroid receptor coactivators: servants and masters for control of systems metabolism. Trends Endocrinol Metab. 2014; 25:337-347.

55. Motamed M, Rajapakshe KI, Hartig SM, Coarfa C, Moses RE, Lonard DM, O'Malley BW. Steroid receptor coactivator 1 is an integrator of glucose and NAD $+/ \mathrm{NADH}$ homeostasis. Molecular Endocrinology. 2014; 28:395-405.

56. Louie MC, Revenko AS, Zou JX, Yao J, Chen HW. Direct control of cell cycle gene expression by proto-oncogene product ACTR, and its autoregulation underlies its transforming activity. Molecular and cellular biology. 2006; 26:3810-3823.

57. Wu D, Yotnda P. Induction and testing of hypoxia in cell culture. Journal of Visualized Experiments. 2011; 54:pii2899.

58. Akhtar N, Dickerson EB, Auerbach R. The sponge/Matrigel angiogenesis assay. Angiogenesis. 2002; 5:75-80.

59. Weidner N, Folkman J, Pozza F, Bevilacqua P, Allred EN, Moore DH, Meli S, Gasparini G. Tumor angiogenesis: a new significant and independent prognostic indicator in early-stage breast carcinoma. Journal of the National Cancer Institute. 1992; 84:1875-1887.

60. Harvey JM, Clark GM, Osborne CK, Allred DC. Estrogen receptor status by immunohistochemistry is superior to the ligand-binding assay for predicting response to adjuvant endocrine therapy in breast cancer. Journal of clinical oncology: official journal of the American Society of Clinical Oncology. 1999; 17:1474-1481. 